\section{Krebsprävention aus dem Gewürzregal}

Das beste Gewürz der Welt sei der Hunger, stellt Miguel de Cervantes fatalistisch in „Don Quixote" fest. Richtig gewürzt kann unsere Nahrung jedoch nicht nur den Hunger vertreiben, sondern die Krebsprävention unterstützen. Verschiedene Substanzen aus dem Kräuter- und Gewürzregal kommen hierbei als potenziell medizinisch wirksam infrage. Die "therapeutische Gewürzmischung" ist somit nicht nur wohlschmeckend, sondern auch antimikrobiell, antifungal, entzündungshemmend, antioxidativ, immunmodulierend und antikarzinogen. Ein bestimmtes Gewürz wird bereits seit mehreren tausend Jahren in der Ayurvedischen Medizin verwendet. Die darin enthaltene bioaktive Verbindung kann unter anderem nachweislich Apoptose induzieren, den Transkriptionsfaktor NF-KB beeinflussen sowie die Produktion des Tumornekrosefaktors (TNF) inhibieren. Ingo Schroeder

Der Buchstabe der richtigen Antwort ist

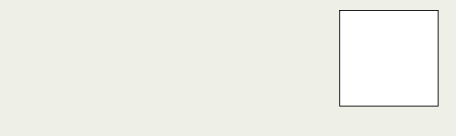

Name

Straße, Nr.

PLZ, Ort

Was ich noch sagen wollte ...

Coupon bitte ausfüllen und abschicken an Springer Medizin, Urban \& Vogel GmbH Redaktion Im Focus Onkologie - Quiz 1/2013 Aschauer Straße 30 • 81549 München Oder senden Sie uns eine E-Mail an doris.berger@springer.com

Einsendeschluss: 19.3.2013

Im Focus Onkologie $2013 ; 16(1-2)$

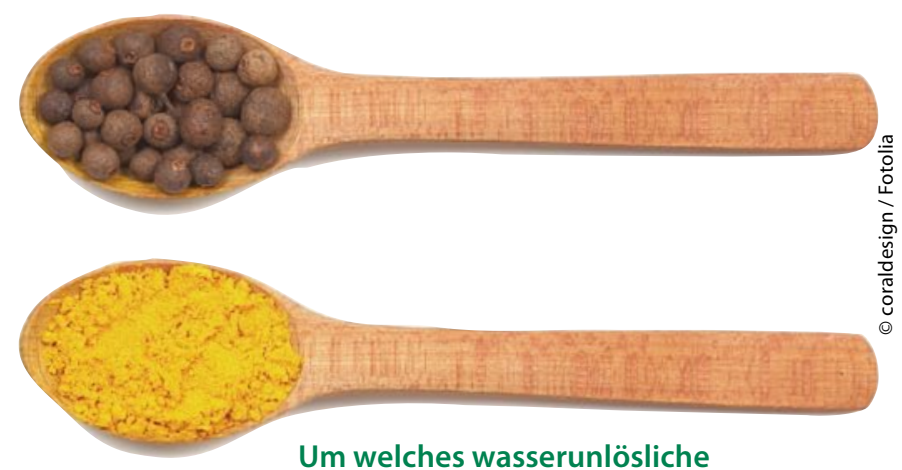

Polyphenol handelt es sich?

A $\beta$-Carotin

B Thymol

C Curcumin
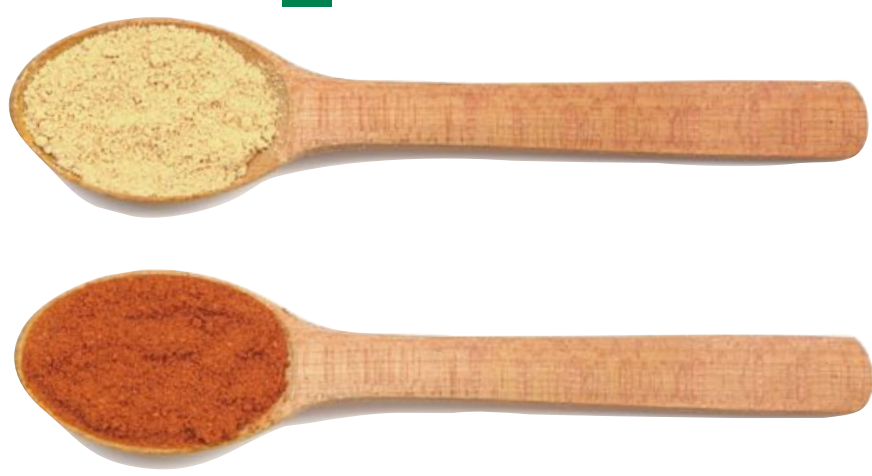

\section{Und das können} Sie gewinnen ...

Alles, was Wissen schafft.

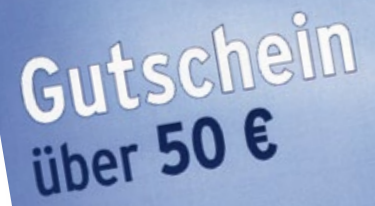

Q Springer Medizin

Unter den richtigen

Einsendungen verlosen

wir drei Gutscheine über

50 Euro, die Sie für ein

beliebiges Springer-Buch einlösen können.

Einsendeschluss ist der

19.3.2013.
Lösung des Quiz 11/2012

Richtig war: C

Die Gewinne gehen an:

C. Buechmann,

73527 Schwäbisch Gmünd

K. Fritsch, 98574 Schmalkalden

T. Döltz, 96049 Bamberg

Herzlichen Glückwunsch! 